\title{
BMJ
}

\section{Human papillomavirus testing in primary cervical screening and the cut-off level for hybrid capture 2 tests: systematic review}

\author{
Matejka Rebolj, postdoctoral researcher, ${ }^{1}$ Jesper Bonde, senior researcher, ${ }^{2,3}$ Sisse Helle Njor, postdoctoral \\ researcher, ${ }^{1}$ Elsebeth Lynge, professor of epidemiology ${ }^{1}$
}

${ }^{1}$ Department of Public Health, University of Copenhagen, Øster Farimagsgade 5, DK-1014 København K, Denmark

${ }^{2}$ Clinical Research Center, Hvidovre Hospital, Hvidovre, Denmark

${ }^{3}$ Department of Pathology, Hvidovre Hospital, Hvidovre, Denmark

Correspondence to: M Rebolj mare@sund.ku.dk

Cite this as: BMJ 2011;342:d2757 doi:10.1136/bmj.d2757

\section{ABSTRACT}

Objective To determine the trade-off between the sensitivity and the specificity for high grade cervical intraepithelial neoplasia at hybrid capture 2 cut-off values above the standard $\geq 1$ relative light units/cut-off level (rlu/co).

Design Systematic review.

Data sources PubMed.

Study selection Randomised controlled trials in primary cervical screening using hybrid capture 2 testing in the intervention arms. Articles published until August 2010 were included if the numbers of women with positive test results and with cervical intraepithelial neoplasia were stratified by hybrid capture 2 cut-off levels.

Participants Women in the baseline screening rounds of the trials.

Interventions Hybrid capture 2 screening in the baseline round including the diagnostic follow-up as practised in the randomised controlled trials and as reported by hybrid capture 2 cut-off values.

Results Owing to heterogeneity in the trials, meta-analysis was not possible. Including cut-off values up to $\geq 10 \mathrm{rlu} / \mathrm{co}$, 25 observation points were available for analysis. The relative sensitivity for cervical intraepithelial neoplasia grade III or higher at cut-off levels of $\geq 2, \geq 4$ or $\geq 5$, and $\geq 10 \mathrm{rlu} /$ co compared with a cut-off level of $\geq 1$ rlu/co varied by trial, but at their lowest they were $0.97,0.92$, and 0.91 , respectively. A similar pattern was observed for cervical intraepithelial neoplasia grade II or higher. The specificity would increase by at least $1 \%, 2 \%$, and $3 \%$, respectively, so that up to $24 \%, 39 \%$, and $53 \%$, of positive hybrid capture 2 test results not associated with high grade neoplasia could be avoided. Only two outliers existed to this general pattern.

Conclusions Although the data were derived from the baseline screening rounds only, the decrease in the sensitivity for high grade cervical intraepithelial neoplasia using a hybrid capture 2 cut-off level between $\geq 2$ rlu/co and $\geq 10 \mathrm{rlu} /$ co seemed acceptable given the international recommendations for testing for human papillomavirus DNA in cervical screening, which require $90 \%$ or more sensitivity for cervical intraepithelial neoplasia grade II or higher compared with hybrid capture
2 at $\geq 1 \mathrm{rlu} / \mathrm{co}$. The data suggest that the hybrid capture 2 cut-off level could be increased in primary screening; this seems reasonably safe and is significantly less burdensome for women.

\section{INTRODUCTION}

The purpose of cervical screening is to decrease the burden of cervical cancer. Since the 1960s, cytology based cervical screening has led to major reductions in the incidence of cervical cancer and related mortality. ${ }^{1}$ The method is not highly sensitive, however, and several countries, including the United Kingdom, are considering making the transition to human papillomavirus based screening. Although infection with high risk human papillomavirus is a necessary step in the development of cervical cancer, most infections clear spontaneously. Consequently a diagnosis of an infection is on its own not adequately specific for identification of progressive cervical intraepithelial neoplasia. ${ }^{2}$ This may increase the need for repeated testing and the workload for general practitioners and gynaecologists. ${ }^{3}$ To maximise the benefit of testing for human papillomavirus DNA in cervical screening, a practical diagnostic algorithm that avoids positive human papillomavirus findings in women with no or inconsequential cervical intraepithelial neoplasia is therefore warranted.

Hybrid capture 2 (Qiagen, Gaithersburg, Maryland) using the threshold of $\geq 1$ relative light units/cut off (rlu/co) is a clinically validated US Food and Drug Administration approved test for detection of human papillomavirus DNA, with a high sensitivity for high grade cervical intraepithelial neoplasia. Compared with cytology, hybrid capture 2 has an estimated relative sensitivity for detection of cervical intraepithelial neoplasia grade III or higher of 1.32 (95\% confidence interval 1.06 to 1.64$).{ }^{4}$ Hybrid capture 2 detects DNA from 13 human papillomavirus genotypes-16, 18, 31, $33,35,39,45,51,52,56,58,59$, and 68 - of which 12 are considered to be high risk for humans and one probably carcinogenic. ${ }^{5}$ Recommendations for screening women aged 30 or more use the hybrid capture 2 's levels of sensitivity for cervical intraepithelial 
neoplasia grade II or higher, its specificity, and its reproducibility as a standard to which new tests for human papillomavirus DNA should be compared. ${ }^{6}$ To avoid positive hybrid capture 2 test results not associated with neoplasia, several authors have evaluated hybrid capture 2 screening strategies with the cut-off level for a positive test result above the standard $\geq 1$ $\mathrm{rlu} / \mathrm{co}$. These authors assessed the trade-offs between a decrease in the sensitivity, measured as the detection of cervical intraepithelial neoplasia, and an improvement in the specificity, measured as the test's positive predictive value. For example, using the hybrid capture 2 with a cut-off level of $\geq 1 \mathrm{rlu} / \mathrm{co}$ among women aged 35 to 60 in the combined Italian phases 1 and 2 randomised controlled trials, the sensitivity for cervical intraepithelial neoplasia grade III or higher was significantly increased compared with cytology: relative sensitivity $1.52(95 \%$ confidence interval 1.06 to $2.19)$. The positive predictive value was significantly lower: relative positive predictive value 0.63 (95\% confidence interval 0.44 to 0.89 ). Using the cut-off level of $\geq 2 \mathrm{rlu} / \mathrm{co}$, the relative sensitivity was similar, at 1.50 (1.04 to 2.16), whereas the relative positive predictive value increased to 0.81 (0.56 to 1.15$).^{7}$ Similar studies have been undertaken, using data from other randomised controlled trials. ${ }^{8-10}$

The studies have not produced a unanimous answer on whether and to what extent the cut-off level using the hybrid capture 2 could be increased. This may be related to several methodological factors. Firstly, some studies defined a positive test result as a referral for colposcopy, whereas others accounted for all women recommended for follow-up. ${ }^{3}$ These differences in the definition of a positive screening test result make a comparison across studies difficult. Secondly, the outcomes at increased hybrid capture 2 thresholds were typically compared with the outcomes of cytology screening, and as the sensitivity of cytology varies among laboratories this type of evaluation may not allow a generalised conclusion on the optimal cut-off level using hybrid capture 2. Finally, several studies observed screening outcomes at a single increased hybrid capture 2 cut-off level (for example, $\geq 2 \mathrm{rlu} / \mathrm{co})^{78}$ rather than across a wider range. We systematically determined the trade-offs between the sensitivity and the specificity for detection of cervical intraepithelial neoplasia for hybrid capture 2 at a range of increased cut-off levels compared with the standard $\geq 1 \mathrm{rlu} / \mathrm{co}$. We focused on published data derived from baseline screening rounds of the randomised controlled trials using hybrid capture 2 in primary cervical screening because these population based data have been in the forefront of the currently ongoing discussions on the future of cervical screening. In contrast with previous studies, we used standard methods to ensure that the outcomes could be compared.

\section{METHODS}

We used PubMed to search for data published until the end of August 2010 deriving from randomised controlled trials using tests for the detection of human papillomavirus DNA in primary cervical screening.
To improve the sensitivity for relevant articles we adopted a two step search strategy. The first step was used to identify all randomised controlled trials using human papillomavirus DNA tests in primary screening populations. The second step was used to obtain a comprehensive overview of articles published from the identified randomised controlled trials. For this search we used trial acronyms if these were listed in the randomised controlled trial registers, ${ }^{11} 12$ otherwise we also searched under the names of the principal investigators, contacts for the trial, or heads of organisations running the trials. ${ }^{11-17}$ In both steps we screened the retrieved abstracts to identify all potentially relevant papers, for which we subsequently retrieved full text publications. See web extra for the search strategies for both steps.

\section{Statistical analysis}

Owing to various differences in the designs of the trials ${ }^{18}$ we refrained from carrying out a traditional meta-analysis and opted for a separate presentation of the results from each trial in a structured format. Using a prespecified table format (table 1), two researchers independently retrieved the numbers of women included in the trials, those with a positive hybrid capture 2 test result, and those with histologically diagnosed cervical intraepithelial neoplasia grades I, II, and III or higher at each reported cut-off level and for each reported age group. Information on follow-up procedures and on ascertainment of cervical intraepithelial neoplasia was also obtained during this process.

We defined a hybrid capture 2 test result as positive if any test was at or above the analysed cut-off level, regardless of the subsequent follow-up recommendations (immediate colposcopy or repeated testing). ${ }^{3} \mathrm{We}$ defined a positive test result not followed by a diagnosis of the studied cervical intraepithelial neoplasia as a false positive. If followed up properly, these women would all have undergone repeated testing or colposcopy. We calculated, by grade of cervical intraepithelial neoplasia, the detection rates (numbers of women with detected neoplasia per 100000 women), the relative sensitivity, the relative specificity, and the relative risks of false positive test results at increased hybrid capture 2 cut-off levels, using the number of women with positive test results and the detection of cervical intraepithelial neoplasia at $\geq 1 \mathrm{rlu} / \mathrm{co}$ as the reference values. The $95 \%$ confidence intervals were calculated by assuming a binomial distribution of the studied events.

\section{RESULTS}

The first step of the search identified 275 articles (fig 1). After screening of the abstracts, 35 full text articles were retrieved. Eleven randomised controlled trials that used testing for human papillomavirus DNA in primary screening were identified this way. Two of the trials ${ }^{1920}$ did not use hybrid capture 2 and one included a selected group of women who had not responded to previous invitations. ${ }^{21}$ These three trials were excluded from further searches. For the remaining 
Table 1|Randomised controlled trials with hybrid capture 2 based screening: numbers of women with positive test results at various cut-off levels, and with detected cervical intraepithelial neoplasia grade III or higher, grade II, and grade I

\begin{tabular}{|c|c|c|c|c|c|}
\hline \multirow[b]{2}{*}{ Trial (age range) } & \multirow{2}{*}{$\begin{array}{l}\text { Hybrid capture } \\
2 \text { cut-off level } \\
\text { (rlu/co) }\end{array}$} & \multirow{2}{*}{$\begin{array}{c}\text { No of women } \\
\text { with positive } \\
\text { test result }\end{array}$} & \multicolumn{3}{|c|}{ Cervical intraepithelial neoplasia grade } \\
\hline & & & III or higher & II & 1 \\
\hline \multirow{4}{*}{ Italian phase $1(25-34)^{27}$} & $\geq 1$ & 836 & 15 & 39 & 122 \\
\hline & $\geq 2$ & 730 & 15 & 39 & 114 \\
\hline & $\geq 4$ & 664 & 15 & 37 & 112 \\
\hline & $\geq 10$ & 575 & 14 & 35 & 101 \\
\hline \multirow{4}{*}{ Italian phase $2(25-34)^{7}$} & $\geq 1$ & 907 & 24 & 44 & 133 \\
\hline & $\geq 2$ & 796 & 24 & 43 & 121 \\
\hline & $\geq 4$ & 703 & 23 & 43 & 112 \\
\hline & $\geq 10$ & 615 & 23 & 41 & 98 \\
\hline \multirow{4}{*}{ UK trial $(20-64)^{14}$} & $\geq 1$ & 3813 & 304 & 244 & NA \\
\hline & $\geq 2$ & 3200 & 300 & 234 & NA \\
\hline & $\geq 4$ & 2816 & 293 & 229 & NA \\
\hline & $\geq 10$ & 2358 & 282 & 216 & NA \\
\hline \multirow{4}{*}{ Italian phase $1(35-60)^{28}$} & $\geq 1$ & 1185 & 38 & 35 & 118 \\
\hline & $\geq 2$ & 908 & 37 & 35 & 98 \\
\hline & $\geq 4$ & 738 & 35 & 34 & 85 \\
\hline & $\geq 10$ & 572 & 35 & 33 & 65 \\
\hline \multirow{4}{*}{ Italian phase $2(35-60)^{7}$} & $\geq 1$ & 1029 & 35 & 34 & 103 \\
\hline & $\geq 2$ & 789 & 35 & 30 & 82 \\
\hline & $\geq 4$ & 647 & 33 & 27 & 68 \\
\hline & $\geq 10$ & 533 & 29 & 22 & 54 \\
\hline \multirow{8}{*}{ Finnish trial $(30-60)^{10}$} & $\geq 1$ & 1475 & 22 & 55 & 46 \\
\hline & $\geq 2$ & 1221 & 22 & 55 & 46 \\
\hline & $\geq 3$ & 1110 & 22 & 55 & 44 \\
\hline & $\geq 5$ & 972 & 21 & 52 & 44 \\
\hline & $\geq 10$ & 797 & 20 & 50 & 42 \\
\hline & $\geq 50$ & 500 & 18 & 44 & 31 \\
\hline & $\geq 250$ & 246 & 8 & 24 & 25 \\
\hline & $\geq 1000$ & 84 & 5 & 17 & 0 \\
\hline
\end{tabular}

NA=not available.

eight randomised controlled trials, the search in the second step retrieved 471 articles (fig 1). The abstracts were checked and 34 full text articles were retrieved. For three trials, no article was found stratifying the number of women with positive screening tests and the number of women with detected cervical intraepithelial neoplasia by hybrid capture 2 cut-off level, and from one trial these data were not stratified in enough detail. ${ }^{82-26}$ Finally, in five articles from four trials the relevant outcomes were reported by hybrid capture 2 cut-off level in the baseline round of the intervention arms: one from Finland, ${ }^{10}$ one from the United Kingdom, ${ }^{9}$ one from Italy (phase 2 trial), ${ }^{7}$ and two from Italy (phase 1 trial). ${ }^{2728}$ Hybrid capture 2 data from the UK trial, however, were stratified in greater detail in a publication combining data from the intervention and control arms (in the control arm of the UK trial, the outcome of hybrid capture 2 testing was available but concealed for the purpose of the management of women), ${ }^{14}$ and we used these latter data. In none of the trials were data from the subsequent screening round stratified by hybrid capture 2 cut-off level. All four trials with the relevant data were undertaken within established organised screening programmes and included previously screened women after an invitation for screening. Taking into account the observed loss to follow-up, ascertainment of diagnoses in women with abnormal screening test results was complete in all trials except for Finland, where data have not been reported by cut-off level for women with a positive hybrid capture 2 test result with triage cytology less severe than low grade squamous intraepithelial neoplasia. The processes of obtaining reference diagnoses varied by study and are summarised in table 2 .

Proportion of women with a positive screening test result The numbers of women with a positive test result and the numbers of cervical intraepithelial neoplasia grade III or higher and grade II or higher could be extracted from all trials (table 1). The proportions of positive hybrid capture 2 test results varied by trial but were consistently lower in trials including only women older than 30 (fig 2). The hybrid capture 2 test was positive at $\geq 1 \mathrm{rlu} / \mathrm{co}$ in $7.1 \%$ and $5.8 \%$ of women in the Italian phase 1 and phase 2 trials (35-60 years), respectively, and in $8.0 \%$ in the Finnish trial (30-60 years). The test result was positive in $13.9 \%$ of women in the Italian phase 1 trial (25-34 years), 13.1\% in the Italian phase 2 trial (25-34 years), and 15.6\% in the UK trial (20-64 years). The proportion of women with a positive hybrid capture 2 test decreased by increased cut-off levels in all trials.

Relative sensitivity for cervical intraepithelial neoplasia by hybrid capture 2 cut-off level

At a cut off of $\geq 1 \mathrm{rlu} / \mathrm{co}$, the detection rates of cervical intraepithelial neoplasia grade III or higher varied between 119 and 1240 per 100000 screened women (fig 2). Per 100000 women screened the detection rates of cervical intraepithelial neoplasia grade II varied between 192 and 996 and those of cervical intraepithelial neoplasia grade I varied between 249 and 2033, underlining the variability of the studied populations, the subjective nature of cervical intraepithelial neoplasia diagnosis, and the variability in the completeness of reported data. Despite the described intertrial variation in the detection rates of cervical intraepithelial neoplasia grade III or higher and grade II or higher, similar relative sensitivities compared with a cut-off level $\geq 1 \mathrm{rlu}$ /co were observed when the threshold was increased (see web extra figure). Throughout the range of cut-off levels up to $\geq 10$ $\mathrm{rlu} / \mathrm{co}$, the relative sensitivities for cervical intraepithelial neoplasia grade III or higher and for grade II or higher were consistently at least $90 \%$ compared with $\geq 1 \mathrm{rlu} /$ co in all trials except one (table 3 ).

At cut-off level $\geq 2 \mathrm{rlu} / \mathrm{co}$, the relative sensitivity for cervical intraepithelial neoplasia grade III or higher in the Italian phase 1 trial (35-60 years) was 0.97 . The relative sensitivity for cervical intraepithelial neoplasia grade II or higher in the UK trial was 0.97 , and in the Italian phase 2 trial (35-60 years) it was 0.94 . In all other reviewed trials the relative sensitivity for cervical 
intraepithelial neoplasia grade III or higher and for grade II or higher was closer to 1 .

At cut-off level $\geq 4 \mathrm{rlu} / \mathrm{co}(\geq 5 \mathrm{rlu} / \mathrm{co}$ in the Finnish trial), the relative sensitivity for cervical intraepithelial neoplasia grade III or higher ranged between 0.92 in the Italian phase 1 trial (35-60 years) and 1.00 in the Italian phase 1 trial (25-34 years). The relative sensitivity for cervical intraepithelial neoplasia grade II or higher in the Italian phase 2 trial (35-60 years) was 0.87 . In other trials, the relative sensitivity for cervical intraepithelial neoplasia grade II or higher ranged between 0.95 (UK, Italian phase 1 (35-60 years), Finland) and 0.97 (Italian phase 2, 25-34 years).

At cut-off level $\geq 10 \mathrm{rlu} / \mathrm{co}$, the relative sensitivity for cervical intraepithelial neoplasia grade III or higher was the lowest in the Italian phase 2 trial (35-60 years), at 0.83 . In other trials, the relative sensitivity for cervical intraepithelial neoplasia grade III or higher varied between 0.91 (Finland) and 0.96 (Italian phase 2, 25-34 years). The relative sensitivity for cervical intraepithelial neoplasia grade II or higher was again the lowest in the Italian phase 2 trial (35-60 years), at 0.74 , whereas in the other trials it ranged between 0.91 (UK, Italian phase 1 (25-34 years), Finland) and 0.94 (Italian phase 2, 25-34 years). At higher cut-off levels in the Finnish trial, the relative sensitivity for any grade of cervical intraepithelial neoplasia decreased substantially.

The relative sensitivity for cervical intraepithelial neoplasia grade I tended to be more substantially decreased at increased cut-off level, although more so in the Italian trials than in the Finnish trial (table 3). At cut-off level $\geq 4 \mathrm{rlu} / \mathrm{co}$ ( $\geq 5 \mathrm{rlu} / \mathrm{co}$ in the Finnish trial), the relative sensitivities for cervical intraepithelial neoplasia grade I were 0.92 and 0.84 in the Italian phases 1 and 2 trials (25-34 years), 0.72 and 0.66 in the Italian phases 1 and 2 trials (35-60 years), and 0.96 in the Finnish trial. At cut-off level $\geq 10 \mathrm{rlu} / \mathrm{co}$ the relative sensitivities were $0.83,0.74,0.55,0.52$, and 0.91 , respectively.

Relative specificity for cervical intraepithelial neoplasia by hybrid capture 2 cut-off level

At all increased cut-off levels, the specificity for cervical intraepithelial neoplasia grade III or higher increased significantly (table 3 , web extra figure). At cut-off level $\geq 2 \mathrm{rlu} / \mathrm{co}$, the specificity increased within a range of $1 \%$ (Italian phase 2 (35-60 years), and Finland) and $3 \%$ (UK trial). At cut-off level $\geq 4 \mathrm{rlu} / \mathrm{co}(\geq 5 \mathrm{rlu} / \mathrm{co}$ in Finland), the specificity increased within a range of $2 \%$ (Italian phase 2, 35-60 years) and 5\% (UK trial), and at cut-off level $\geq 10 \mathrm{rlu} / \mathrm{co}$ it increased within a range of 3\% (Italian phase 2, 35-60 years) and 7\% (UK trial). Similar numbers were found for cervical intraepithelial neoplasia grade II or higher as end point.

These gradual increases in the specificity were reflected in the considerably reduced risks of false positive hybrid capture 2 test results (fig 3). When cervical intraepithelial neoplasia grade III or higher was used as an end point, for example, the relative proportions compared with $\geq 1 \mathrm{rlu} / \mathrm{co}$ at cut-off level $\geq 10 \mathrm{rlu} / \mathrm{co}$ were 0.68 and 0.67 in the Italian phases 1 and 2 trials
(25-34 years), 0.59 in the UK trial, 0.47 and 0.51 in the Italian phases 1 and 2 trials (35-60 years), and 0.53 in the Finnish trial. Similar results were obtained for other grades of cervical intraepithelial neoplasia (data not shown).

\section{DISCUSSION}

Recently published international recommendations for screening women aged 30 or more for human papillomavirus require that new tests to detect human papillomavirus DNA show at least a 90\% sensitivity for cervical intraepithelial neoplasia grade II or higher compared with the sensitivity of hybrid capture 2 testing using the cut-off level $\geq 1 \mathrm{rlu} / \mathrm{co},{ }^{6}$ and according to Kinney et al, the sensitivity of human papillomavirus screening for cervical intraepithelial neoplasia grade III or higher should be above $90 \% .^{2}$ Our reanalysis of the reported trial data showed that hybrid capture 2 testing using the range of increased cut-off levels between $\geq 2 \mathrm{rlu} / \mathrm{co}$ and $\geq 10 \mathrm{rlu} / \mathrm{co}$ is able to meet

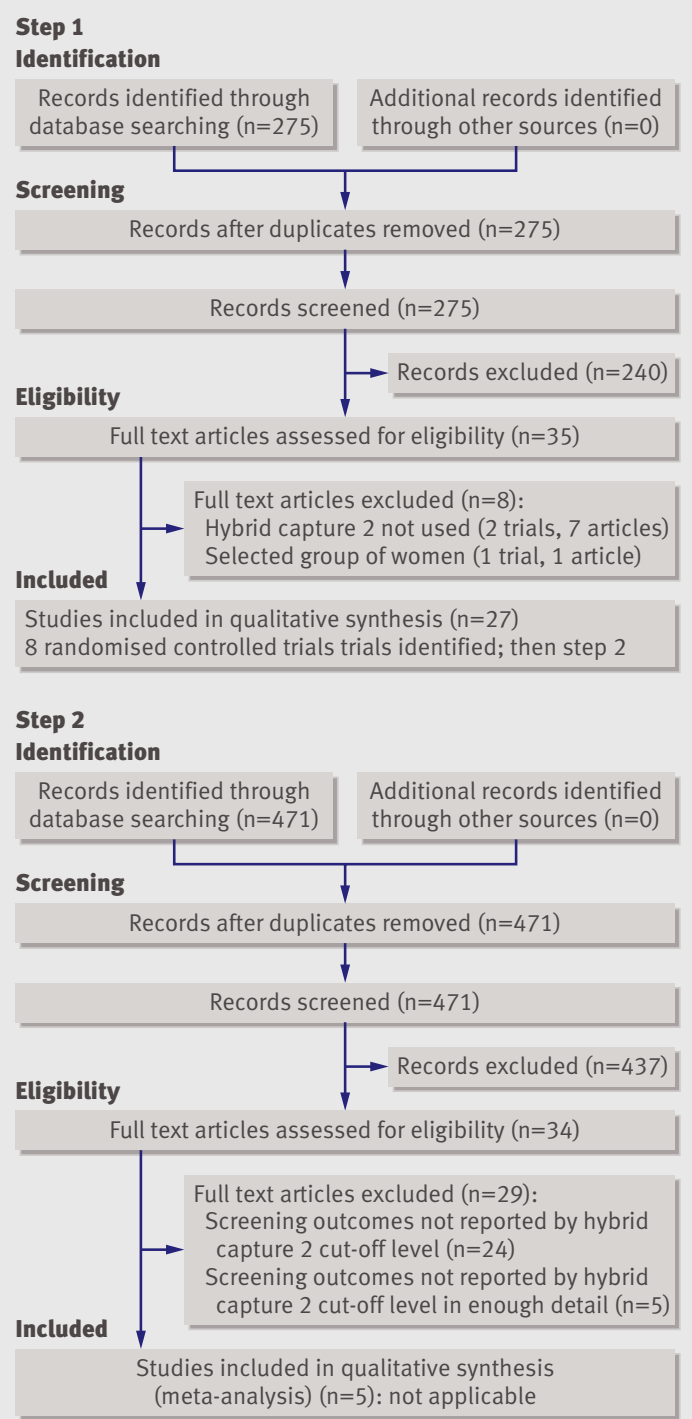

Fig 1| Study selection 
Table $2 \mid$ Reported data on follow-up procedures from randomised controlled trials

\begin{tabular}{|c|c|c|c|c|c|c|}
\hline Trial & Acronym & $\begin{array}{l}\text { Age range } \\
\text { (years) }\end{array}$ & $\begin{array}{c}\text { No in intervention } \\
\text { arm }\end{array}$ & $\begin{array}{l}\text { Follow-up recommendations after positive } \\
\text { hybrid capture } 2 \text { test result }(\geq 1 \mathrm{rlu} / \mathrm{co})\end{array}$ & $\begin{array}{l}\text { Compliance with follow-up } \\
\text { recommendations }\end{array}$ & Reported histology \\
\hline Italian phase $1^{27}$ & NTCC 1 & $25-34$ & 6002 & $\begin{array}{l}\text { Cytology normal: repeat testing at } 12 \text { months; } \\
\text { atypical squamous cells of undetermined } \\
\text { significance or worse: colposcopy }\end{array}$ & $\begin{array}{l}\text { Cytology normal: } 62 \% \text {; atypical } \\
\text { squamous cells of undetermined } \\
\text { significance or worse: } 94 \%\end{array}$ & $\begin{array}{l}\text { Consensus diagnosis } \leq 1 \text { year of } \\
\text { referral for colposcopy (immediate } \\
\text { or after repeated testing) }\end{array}$ \\
\hline Italian phase $1^{27}$ & NTCC 2 & $25-34$ & 6937 & Colposcopy & $94 \%$ & $\begin{array}{l}\text { Consensus diagnosis } \leq 1 \text { year of } \\
\text { referral for colposcopy (immediate } \\
\text { or after repeated testing) }\end{array}$ \\
\hline UK trial $^{14}$ & ARTISTIC & $20-64$ & $24510^{\star}$ & $\begin{array}{l}\text { Intervention arm: cytology normal: repeat } \\
\text { testing at } 12 \text { months; borderline or mildly } \\
\text { abnormal: repeat testing at six months; } \\
\text { moderately abnormal or worse: colposcopy. } \\
\text { Control arm: borderline or mildly abnormal: } \\
\text { repeat testing at six months; moderately } \\
\text { abnormal or worse: colposcopy }\end{array}$ & $\begin{array}{l}\text { Intervention arm: cytology normal: } \\
55 \% \text {. Other: NA }\end{array}$ & $\begin{array}{l}\text { Worst diagnosis in } \leq 30 \text { months of } \\
\text { abnormal round } 1 \text { sample }\end{array}$ \\
\hline Italian phase $1^{28}$ & NTCC 1 & $35-60$ & 16706 & Colposcopy & $93 \%$ & $\begin{array}{l}\text { Consensus diagnosis } \leq 1 \text { year of } \\
\text { referral for colposcopy (immediate } \\
\text { or after repeated testing) }\end{array}$ \\
\hline Italian phase $2^{7}$ & NTCC 2 & $35-60$ & 17724 & Colposcopy & $93 \%$ & $\begin{array}{l}\text { Consensus diagnosis } \leq 1 \text { year of } \\
\text { referral for colposcopy (immediate } \\
\text { or after repeated testing) }\end{array}$ \\
\hline Finnish trial ${ }^{10}$ & NA & $30-60$ & 18438 & $\begin{array}{l}\text { Cytology normal or atypical squamous cells of } \\
\text { undetermined significance: repeat testing at } \\
12 \text { months; low grade squamous } \\
\text { intraepithelial lesions† or worse: colposcopy }\end{array}$ & NA & NA \\
\hline
\end{tabular}

$\mathrm{NA}=$ not available.

*Intervention and control arm combined.

†Histology not reported for women with cytology less severe than low grade squamous intraepithelial lesions.

these requirements. Using the cut-off level $\geq 2 \mathrm{rlu} / \mathrm{co}$ instead of $\geq 1 \mathrm{rlu} / \mathrm{co}$, up to $3 \%$ of cervical intraepithelial neoplasia grade II or higher and of grade III or higher detectable at cut-off level $\geq 1 \mathrm{rlu} /$ co would not be detected at the given screen. Up to $8 \%$ of cervical intraepithelial neoplasia grade II or higher and of grade III or higher would not be detected at the given screen if the cut-off levels $\geq 4$ or $\geq 5 \mathrm{rlu} /$ co were used, and up to $9 \%$ if the cut-off level $\geq 10 \mathrm{rlu} / \mathrm{co}$ was used. The specificity of the hybrid capture 2 test was significantly increased with increased cut-off levels, reflecting a significantly reduced risk of false positive test results. At cut-off level $\geq 10 \mathrm{rlu} / \mathrm{co}$, this risk was reduced by about one half among women aged 30 or more, whereas among younger women the reduction was about one third. The observed patterns were consistent across trials, with the only exception being the Italian phase 2 trial for women aged 35 to 60 . In this trial, $17 \%$ of the cervical intraepithelial neoplasia grade III or higher would be missed at cut-off level $\geq 10 \mathrm{rlu} / \mathrm{co}$. Owing to the relatively low number of cervical intraepithelial neoplasia grade II or higher and of grade III or higher reported from most trials, the calculated 95\% confidence intervals for relative sensitivities were wide.

\section{Limitations of the study}

No reported data sufficiently stratified by hybrid capture 2 cut-off level could be identified from four randomised controlled trials, of which two were undertaken in previously unscreened women, ${ }^{2526}$ one was not undertaken within an organised screening programme, ${ }^{8}$ and one has not yet completed its recruitment. ${ }^{22}$ The outcomes presented in this systematic review may therefore not be generalisable to settings with opportunistic screening and settings with previously unscreened women. Some of the data from the four trials included in this systematic review have been incompletely reported. For instance, data on lesions detected during the extended follow-up in the two Italian trials ${ }^{29}$ have not been reported by baseline cut-off levels, and data on lesions detected during follow-up with repeated testing of women with triage cytology less severe than low grade squamous intraepithelial lesions have not been reported by cut-off level from the Finnish trial..$^{30}$ It could be argued that in the reported data from the Finnish trial, the detection of cervical intraepithelial neoplasia grade I was particularly low because only women positive for human papillomavirus and with at least low grade squamous intraepithelial neoplasia on cytology were referred for colposcopy.

Detection of cervical intraepithelial neoplasia depends on the follow-up procedures for women who were positive at hybrid capture 2 cut-off level $\geq 1$ $\mathrm{rlu} / \mathrm{co}$, and these procedures varied by trial (table 2 ). In the Italian phase 2 trial, all of these women were immediately referred for colposcopy, whereas in the Italian phase 1 trial they were immediately referred for colposcopy only if they were older than 34 or had abnormal cytology, in the Finnish trial if the cytology was low grade squamous intraepithelial neoplasia or worse, and in the UK trial if the cytology was at least moderately abnormal. In trials with reported data, more than $90 \%$ of the immediately referred women had colposcopy. Women with a positive hybrid capture 2 test result not immediately referred for colposcopy were recommended to undergo repeated testing in six to 12 months, and only $55 \%$ in the UK 


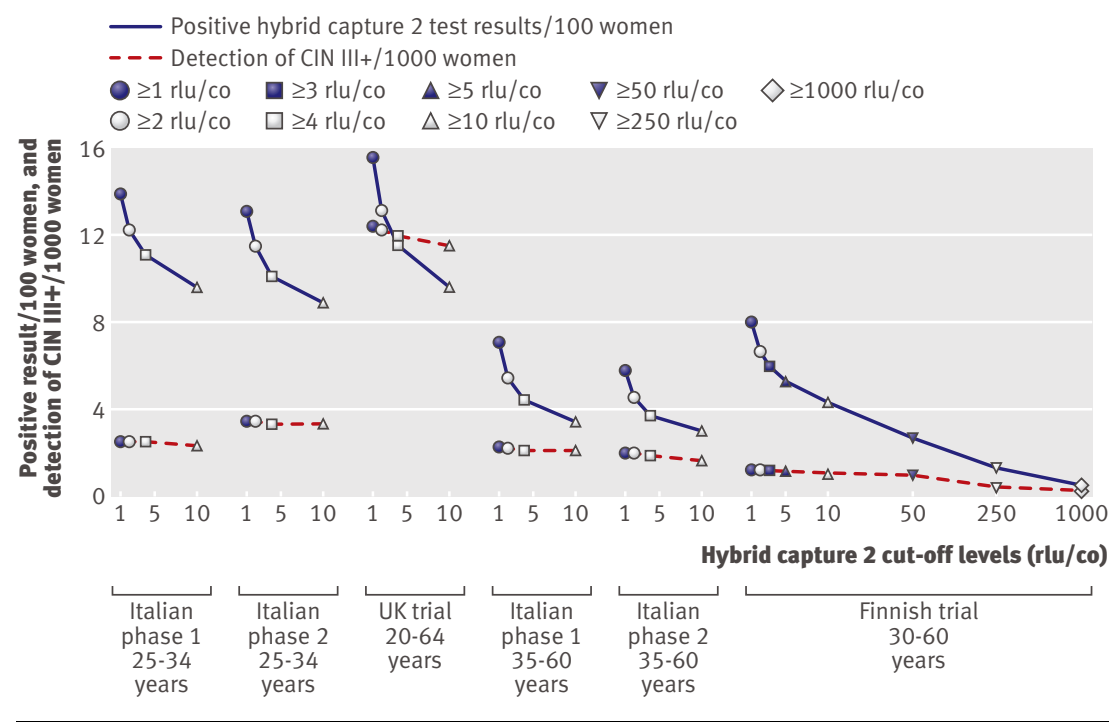

Fig 2 Percentage of women with positive hybrid capture 2 test results, and detection rates of cervical intraepithelial neoplasia grade III or higher (CIN III+) per 1000 women screened, by hybrid capture 2 cut-off level in intervention arms of reviewed randomised controlled trials (intervention+control arm in UK trial)

trial and $62 \%$ in the Italian phase 1 trial had the repeated test and a colposcopy if the repeated test result was positive. Despite this variability in the follow-up strategies across trials, the trade-offs between the indicators of sensitivity and specificity at increased hybrid capture 2 cut-off levels were similar.

It should be taken into account that women in the intervention arms of the trials were predominantly managed according to the hybrid capture 2 cut-off level $\geq 1$ $\mathrm{rlu} / \mathrm{co}$. Thus, these data did not allow for a direct comparison of the long term negative predictive values at different cut-off levels. The excellent negative predictive values found at cut-off level $\geq 1 \mathrm{rlu} /$ co suggested that the screening intervals could be extended from the current three to five years with cytology to 6 to 7 . 5 years using human papillomavirus DNA testing. ${ }^{3132}$ Theoretically, increasing the cut-off level may not allow precisely the same extension of the screening interval. Many cervical intraepithelial neoplasia grades III and II though do not progress to cervical cancer. When they do, the progression is gradual and on average takes more than 10 years. ${ }^{33-35}$ The increased cut-off level is therefore not expected to substantially decrease the effectiveness of hybrid capture 2 . Similar precaution needs to be taken when the sensitivity of new human papillomavirus DNA tests will be compared with hybrid capture 2 using the published guidelines. ${ }^{6}$

\section{Other studies}

Screening outcomes stratified by hybrid capture 2 cutoff level have been reported also from several split sample studies in which women were screened with both hybrid capture 2 and cytology. In general, these studies corroborated the findings from the randomised controlled trials. For example, among the 10358 women aged 30 to 60 in the HART study, 67 had a diagnosis of cervical intraepithelial neoplasia grade
III or higher after a positive hybrid capture 2 test result using the cut-off level $\geq 1 \mathrm{rlu} / \mathrm{co}$. In $93 \%$ of these 67 women $(62 / 67 ; 95 \%$ confidence interval $83 \%$ to $98 \%$ ), the hybrid capture 2 test result was positive at $\geq 10 \mathrm{rlu} / \mathrm{co}$. At this cut-off level, 40\% fewer women had a false positive test result compared with a cut-off level $\geq 1 \mathrm{rlu} /$ co $(428 / 717 ; 37 \%$ to $44 \%) .{ }^{36}$ In a French study of 7932 females screened aged 15 to $76,96 \%$ of cervical intraepithelial neoplasia grade II or higher was detected with a hybrid capture 2 cut-off level $\geq 3 \mathrm{rlu} / \mathrm{co}$ $(124 / 129 ; 91 \%$ to $99 \%)$, although at the cut-off level $\geq 10 \mathrm{rlu} / \mathrm{co}$ this proportion decreased to $88 \%$ (114/ $129 ; 82 \%$ to $93 \%) .{ }^{37}$ In 1999 Finnish females aged 15 to 86 referred for various gynaecological disorders, the relative sensitivity for cervical intraepithelial neoplasia grade III or higher was $0.86(19 / 22 ; 0.65$ to 0.97$)$ and for grade II or higher it was $0.93(42 / 45 ; 0.82$ to 0.99$)$ at a cut-off level $\geq 5 \mathrm{rlu} /$ co compared with $\geq 1 \mathrm{rlu} / \mathrm{co}^{38}$

Among 9057 previously unscreened women aged 30 to 54 in rural China, 134 had a diagnosis of cervical intraepithelial neoplasia grade III or higher associated with a hybrid capture 2 positive test result at cut-off level $\geq 1 \mathrm{rlu} / \mathrm{co}$ and 125 at cut-off level $\geq 10 \mathrm{rlu} / \mathrm{co}$ (relative sensitivity $0.93,95 \%$ confidence interval 0.88 to 0.97). Although the relative sensitivity was slightly decreased (0.88) when adjustment was applied to account for the differences among the participating centres and verification bias, the authors concluded that using hybrid capture 2 testing with a cut-off level $\geq 10 \mathrm{rlu} / \mathrm{co}$ "might be the most appropriate" screening strategy for areas with basic screening infrastructure that does not allow frequent screening. ${ }^{39}$

Recently, detailed results for a range of hybrid capture 2 cut-off levels were presented from a Dutch VUSA-screen cohort study of 25871 women aged 30 to 60 screened with both hybrid capture 2 and cytology. ${ }^{40}$ In this study, the relative sensitivity for high grade cervical intraepithelial neoplasia and the relative risks of false positive test results with increased hybrid capture 2 cut-off levels were compared with the outcomes of cytology screening. Only women referred for colposcopy were taken into account in the calculation of the risk of false positive test results. This study could not identify any increased hybrid capture 2 cutoff level at which the colposcopy referral rate would be similar to that in cytology screening without at the same time substantially decreasing the test's sensitivity for high grade cervical intraepithelial neoplasia. The authors consequently proposed to keep the $\geq 1 \mathrm{rlu} / \mathrm{co}$ cut-off level. We recalculated the VUSA-screen data using the hybrid capture 2 test with a cut-off level $\geq 1$ $\mathrm{rlu} / \mathrm{co}$ as a reference, and accounting for all positive screening test results in the calculation. At a cut-off level $\geq 10 \mathrm{rlu} / \mathrm{co}$, the relative sensitivity for cervical intraepithelial neoplasia grade III or higher was 0.90 (131/146; 95\% confidence interval 0.84 to 0.94$)$ compared with cut-off level $\geq 1 \mathrm{rlu} / \mathrm{co}$, and the corresponding relative risk of false positive test results was 0.64 (746/1157; 0.62 to 0.67$)$. The relative sensitivity for cervical intraepithelial neoplasia grade II or higher was $0.89(203 / 227 ; 0.85$ to 0.93$)$ and the corresponding 
Table $3 \mid$ Relative sensitivity, relative specificity, and relative risks of false positive test results, by hybrid capture 2 cut-off level

\begin{tabular}{|c|c|c|c|c|c|c|c|}
\hline \multirow[b]{2}{*}{ Trial (age range) } & \multirow[b]{2}{*}{$\begin{array}{l}\text { Hybrid capture } 2 \\
\text { cut-off level (rlu/co) }\end{array}$} & \multicolumn{3}{|c|}{$\begin{array}{l}\text { Cervical intraepithelial neoplasia } \\
\text { grade III or higher }\end{array}$} & \multicolumn{2}{|c|}{$\begin{array}{l}\text { Cervical intraepithelial neoplasia } \\
\text { grade II or higher }\end{array}$} & \multirow{2}{*}{$\begin{array}{c}\text { Cervical } \\
\text { intraepithelial } \\
\text { neoplasia grade I } \\
\text { Relative sensitivity } \\
(95 \% \mathrm{Cl})\end{array}$} \\
\hline & & $\begin{array}{l}\text { Relative sensitivity } \\
\qquad(95 \% \mathrm{Cl})\end{array}$ & $\begin{array}{l}\text { Relative specificity } \\
\qquad(95 \% \mathrm{Cl})\end{array}$ & $\begin{array}{c}\text { Relative risk of } \\
\text { false-positive tests } \\
(95 \% \mathrm{Cl})\end{array}$ & $\begin{array}{l}\text { Relative sensitivity } \\
\qquad(95 \% \mathrm{Cl})\end{array}$ & $\begin{array}{l}\text { Relative specificity } \\
\qquad(95 \% \mathrm{Cl})\end{array}$ & \\
\hline \multirow{4}{*}{$\begin{array}{l}\text { Italian phase } 1 \\
(25-34)\end{array}$} & $\geq 1$ & 1 & 1 & 1 & 1 & 1 & 1 \\
\hline & $\geq 2$ & $1.00(0.78$ to 1.00$)$ & $1.02(1.02$ to 1.02$)$ & 0.87 (0.85 to 0.89$)$ & $1.00(0.93$ to 1.00$)$ & $1.02(1.02$ to 1.02$)$ & $0.93(0.87$ to 0.97$)$ \\
\hline & $\geq 4$ & $1.00(0.78$ to 1.00$)$ & 1.03 (1.03 to 1.04$)$ & 0.79 (0.76 to 0.82$)$ & 0.96 (0.87 to 1.00$)$ & 1.03 (1.03 to 1.04$)$ & 0.92 (0.85 to 0.96$)$ \\
\hline & $\geq 10$ & $0.93(0.68$ to 1.00$)$ & 1.05 (1.04 to 1.06$)$ & 0.68 (0.65 to 0.72$)$ & 0.91 (0.80 to 0.97$)$ & 1.05 (1.04 to 1.06$)$ & 0.83 (0.75 to 0.89 ) \\
\hline \multirow{4}{*}{$\begin{array}{l}\text { Italian phase } 2 \\
(25-34)\end{array}$} & $\geq 1$ & 1 & 1 & 1 & 1 & 1 & 1 \\
\hline & $\geq 2$ & $1.00(0.88$ to 1.00$)$ & 1.02 (1.02 to 1.02$)$ & $0.87(0.85$ to 0.90$)$ & 0.99 (0.92 to 1.00$)$ & 1.02 (1.01 to 1.02$)$ & 0.91 (0.85 to 0.95$)$ \\
\hline & $\geq 4$ & $0.96(0.79$ to 1.00$)$ & 1.03 (1.03 to 1.04$)$ & $0.77(0.74$ to 0.80$)$ & $0.97(0.90$ to 1.00$)$ & $1.03(1.03$ to 1.04$)$ & $0.84(0.77$ to 0.90$)$ \\
\hline & $\geq 10$ & $0.96(0.79$ to 1.00$)$ & 1.05 (1.04 to 1.05$)$ & 0.67 (0.64 to 0.70$)$ & 0.94 (0.86 to 0.98$)$ & 1.05 (1.04 to 1.05$)$ & 0.74 (0.65 to 0.81$)$ \\
\hline \multirow{4}{*}{$\begin{array}{l}\text { UK trial } \\
(20-64)\end{array}$} & $\geq 1$ & 1 & 1 & 1 & 1 & 1 & NA \\
\hline & $\geq 2$ & $0.99(0.97$ to 1.00$)$ & 1.03 (1.03 to 1.03$)$ & $0.83(0.81$ to 0.84$)$ & 0.97 (0.96 to 0.99$)$ & 1.03 (1.03 to 1.03$)$ & NA \\
\hline & $\geq 4$ & $0.96(0.94$ to 0.98$)$ & 1.05 (1.04 to 1.05$)$ & $0.72(0.70$ to 0.73$)$ & 0.95 (0.93 to 0.97$)$ & $1.05(1.04$ to 1.05$)$ & NA \\
\hline & $\geq 10$ & 0.93 (0.89 to 0.95$)$ & 1.07 (1.07 to 1.07$)$ & $0.59(0.58$ to 0.61$)$ & 0.91 (0.88 to 0.93$)$ & 1.07 (1.06 to 1.07$)$ & NA \\
\hline \multirow{4}{*}{$\begin{array}{l}\text { Italian phase } 1 \\
(35-60)\end{array}$} & $\geq 1$ & 1 & 1 & 1 & 1 & 1 & 1 \\
\hline & $\geq 2$ & 0.97 (0.86 to 1.00$)$ & $1.02(1.02$ to 1.02$)$ & $0.76(0.73$ to 0.78$)$ & $0.99(0.93$ to 1.00$)$ & 1.02 (1.02 to 1.02$)$ & $0.83(0.75$ to 0.89$)$ \\
\hline & $\geq 4$ & 0.92 (0.79 to 0.98$)$ & 1.03 (1.03 to 1.03$)$ & 0.61 (0.58 to 0.64$)$ & 0.95 (0.87 to 0.98) & 1.03 (1.03 to 1.03$)$ & $0.72(0.63$ to 0.80$)$ \\
\hline & $\geq 10$ & 0.92 (0.79 to 0.98$)$ & 1.04 (1.04 to 1.04$)$ & $0.47(0.44$ to 0.50$)$ & $0.93(0.85$ to 0.98$)$ & 1.04 (1.04 to 1.04$)$ & $0.55(0.46$ to 0.64$)$ \\
\hline \multirow{4}{*}{$\begin{array}{l}\text { Italian phase } 2 \\
(35-60)\end{array}$} & $\geq 1$ & 1 & 1 & 1 & 1 & 1 & 1 \\
\hline & $\geq 2$ & $1.00(0.90$ to 1.00$)$ & 1.01 (1.01 to 1.02$)$ & $0.76(0.73$ to 0.78$)$ & 0.94 (0.86 to 0.98$)$ & 1.01 (1.01 to 1.02$)$ & $0.80(0.71$ to 0.87$)$ \\
\hline & $\geq 4$ & 0.94 (0.81 to 0.99$)$ & $1.02(1.02$ to 1.03$)$ & $0.62(0.59$ to 0.65$)$ & 0.87 (0.77 to 0.94$)$ & $1.02(1.02$ to 1.02$)$ & $0.66(0.56$ to 0.75$)$ \\
\hline & $\geq 10$ & 0.83 (0.66 to 0.93$)$ & 1.03 (1.03 to 1.03$)$ & $0.51(0.48$ to 0.54$)$ & $0.74(0.62$ to 0.84$)$ & 1.03 (1.03 to 1.03$)$ & $0.52(0.42$ to 0.62$)$ \\
\hline \multirow{8}{*}{$\begin{array}{l}\text { Finnish trial } \\
(30-60)\end{array}$} & $\geq 1$ & 1 & 1 & 1 & 1 & 1 & 1 \\
\hline & $\geq 2$ & $1.00(0.85$ to 1.00$)$ & 1.01 (1.01 to 1.02$)$ & $0.83(0.80$ to 0.84$)$ & $1.00(0.95$ to 1.00$)$ & 1.01 (1.01 to 1.02$)$ & $1.00(0.92$ to 1.00$)$ \\
\hline & $\geq 3$ & $1.00(0.85$ to 1.00$)$ & $1.02(1.02$ to 1.02$)$ & $0.75(0.73$ to 0.77$)$ & $1.00(0.95$ to 1.00$)$ & $1.02(1.02$ to 1.02$)$ & 0.96 (0.85 to 0.99$)$ \\
\hline & $\geq 5$ & 0.95 (0.77 to 1.00$)$ & 1.03 (1.03 to 1.03$)$ & 0.65 (0.63 to 0.68$)$ & 0.95 (0.87 to 0.99) & 1.03 (1.03 to 1.03$)$ & 0.96 (0.85 to 0.99$)$ \\
\hline & $\geq 10$ & 0.91 (0.71 to 0.99$)$ & 1.04 (1.04 to 1.04$)$ & $0.53(0.51$ to 0.56$)$ & 0.91 (0.82 to 0.96$)$ & 1.04 (1.04 to 1.04$)$ & 0.91 (0.79 to 0.98$)$ \\
\hline & $\geq 50$ & $0.82(0.60$ to 0.95$)$ & $1.06(1.05$ to 1.06$)$ & $0.33(0.31$ to 0.36$)$ & 0.81 (0.70 to 0.89$)$ & 1.06 (1.05 to 1.06$)$ & $0.67(0.52$ to 0.80$)$ \\
\hline & $\geq 250$ & $0.36(0.17$ to 0.59$)$ & 1.07 (1.07 to 1.08$)$ & $0.16(0.15$ to 0.18$)$ & $0.42(0.30$ to 0.53$)$ & 1.07 (1.07 to 1.07$)$ & $0.54(0.39$ to 0.69$)$ \\
\hline & $\geq 1000$ & 0.23 (0.08 to 0.45$)$ & 1.08 (1.08 to 1.09$)$ & 0.05 (0.04 to 0.07$)$ & 0.29 (0.19 to 0.40$)$ & 1.08 (1.07 to 1.08$)$ & 0.00 (0.00 to 0.08$)$ \\
\hline
\end{tabular}

NA=not available.

relative risk of false positive test results was $0.63(674 /$ $1076 ; 0.60$ to 0.65$)$. Thus, the VUSA-screen data were in line with the data from the analysed randomised controlled trials, and in fact support using an increased hybrid capture 2 cut-off level in screening.

Effect on cervical intraepithelial neoplasia treatment and the psychosocial burden of screening

If the cut-off level was increased from $\geq 1 \mathrm{rlu} / \mathrm{co}$ to $\geq 10$ $\mathrm{rlu} / \mathrm{co}$, up to 18 fewer women with cervical intraepithelial neoplasia grade III or higher per 100000 screened women would be diagnosed and treated at the given screen in part of the Italian trials and in the Finnish trials. This number was 34 in the Italian phase 2 trial (35-60 years) and 90 in the UK trial, although in the case of the UK trial this still represented less than $10 \%$ of all detected cervical intraepithelial neoplasia grade III or higher at $\geq 1 \mathrm{rlu} / \mathrm{co}$. The rare prevalent cancer cases at a given screening round may, however, be at risk of being missed at any cut-off point. ${ }^{41}$

Even in women over 30, the use of human papillomavirus DNA tests would in many countries double the number of women with a positive screening test result compared with cytology. ${ }^{782028}$ To help manage this increase, several authors have focused on finding optimal triage procedures to avoid excess referral for colposcopy and excess diagnoses, particularly of cervical intraepithelial neoplasia grade II. ${ }^{72}$ This is warranted, as colposcopy tends to be relatively expensive and induces anxiety. ${ }^{43}$ Furthermore, cervical intraepithelial neoplasia grade II is often regressive ${ }^{4445}$ but nevertheless usually recommended for treatment that may be associated with severe obstetric outcomes. ${ }^{46}$ Women with positive human papillomavirus test results who are not immediately referred for colposcopy are normally recommended for repeated testing. These repeated tests increase the workload of general practitioners or gynaecologists and affect women's quality of life. ${ }^{4-49}$ The need for repeated tests could be substantially decreased by using an increased cutoff point. The risk of not detecting a small proportion of cervical intraepithelial neoplasia grade III at a given screening round should thus be interpreted in the light of substantially diminished overdetection of harmless human papillomavirus infections in healthy women. The frequency of such infections can be well 


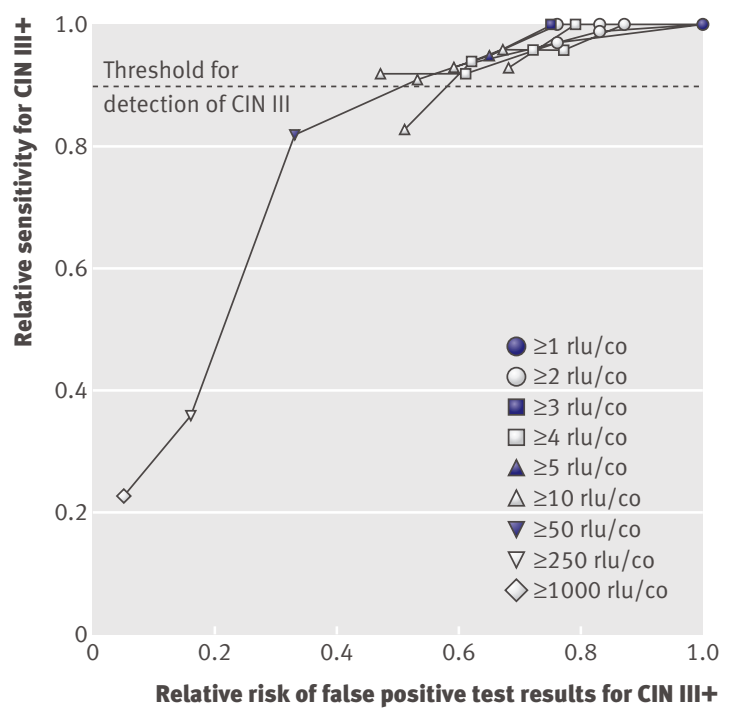

Fig 3 | Relative sensitivity and relative risk of false positive hybrid capture 2 test results using cervical intraepithelial neoplasia grade III or higher (CIN III+) as end point. Comparison of increased hybrid capture 2 thresholds with standard cut-off level $\geq 1$ rlu/co

illustrated with the data from this review. Per 100000 screened women, about 1500 fewer healthy women would have a false positive test result on screening using hybrid capture 2 and remain in follow-up at cutoff level $\geq 2 \mathrm{rlu} /$ co compared with the cut-off level $\geq 1$ rlu/co. Likewise, about 3000 and 4000 fewer healthy women would have a false positive hybrid capture 2 test result if the cut-off level was increased to $\geq 4(\geq 5)$ $\mathrm{rlu} / \mathrm{co}$ and $\geq 10 \mathrm{rlu} / \mathrm{co}$, respectively. These numbers were consistent across the reported trial data. In most settings, treatment of cervical intraepithelial neoplasia grade I is not recommended, ${ }^{50}$ and another benefit of an increased cut-off level for the hybrid capture 2 test is therefore the reduced detection of cervical intraepithelial neoplasia grade I. Using the cut-off level $\geq 10 \mathrm{rlu} / \mathrm{co}$ in both Italian trials, for example, cervical intraepithelial neoplasia grade I diagnoses could be avoided in at least 300 per 100000 screened women.

\section{WHAT IS ALREADY KNOWN ON THIS TOPIC}

Human papillomavirus DNA testing seems to be more sensitive for detection of high grade cervical intraepithelial neoplasia than cytology, but it leads to more positive test results not associated with neoplasia

Hybrid capture 2 with a recommended cut-off value of $\geq 1 \mathrm{rlu} / \mathrm{co}$ is a clinically validated US Food and Drug Administration approved human papillomavirus DNA test

Most of the high grade cervical intraepithelial neoplasia lesions show hybrid capture 2 cut-off values above $\geq 1 \mathrm{rlu} / \mathrm{co}$

\section{WHAT THIS STUDY ADDS}

If the hybrid capture 2 cut-off level was increased from the standard $\geq 1 \mathrm{rlu} / \mathrm{co}$ to $\geq 10 \mathrm{rlu} / \mathrm{co}$, the number of positive test results without underlying high grade cervical intraepithelial neoplasia would be about halved in women aged 30 years or more

The results suggest that it may be possible to increase the cut-off point used for the hybrid capture 2 test in screening without jeopardising its sensitivity for high grade cervical intraepithelial neoplasia, but considerably improving its specificity

\section{Conclusion}

Increasing the cut-off level for a positive hybrid capture 2 test result above the standard $\geq 1 \mathrm{rlu} /$ co is associated with a risk of not detecting some high grade cervical intraepithelial neoplasia as early as it would otherwise have been possible. The trade-offs between decreased sensitivity and increased specificity resulting from increasing the hybrid capture 2 cut-off level, however, seem acceptable according to the recent international recommendations on human papillomavirus DNA testing, and both younger and older women would benefit from this change. In the reported data from most reviewed trials, the relative sensitivity at increased cutoff levels for cervical intraepithelial neoplasia grade II or higher and for grade III or higher would still be $90 \%$ or more compared with $\geq 1 \mathrm{rlu} / \mathrm{co}$. This was the case even when the hybrid capture 2 cut-off level was increased to $\geq 10 \mathrm{rlu} / \mathrm{co}$. At this level, the improvement in the specificity led to about half as many women aged 30 or more and about one third fewer younger women with a false positive hybrid capture 2 test result compared with the standard cut-off level.

We thank Caspar Looman for statistical advice, Brian Larsen Thorsted fo support on visual representation of the data, and Lene Borrits for operationalising the PubMed search strategy.

Contributors: MR and EL designed the study. MR, SHN, and EL analysed the data. All authors interpreted the results, drafted the manuscript, approved the decision to submit the manuscript, and had full access to all of the data in the study. MR is guarantor.

Funding: This work was supported by Olga and Esper Boel's Fund; Aase and Ejnar Danielsen's Fund; Augustinus Fund; Manufacturer Mads Clausen's Fund; Family Hede Nielsen's Fund; Else and Mogens WedellWedellsborg's Fund; Carl and Ellen Hertz's Grant for Danish Medical and Natural Sciences Research; and Merchant Sven Hansen and Mrs Ina Hansen's Fund. None of these had any role in the study design, the collection of data, the analysis, the interpretation of the data, the writing of the paper, and in the decision to submit the paper for publication. Competing interests: All authors have completed the Unified Competing Interest form at www.icmje.org/coi_disclosure.pdf (available on request from the corresponding author) and declare: support from the Olga and Esper Boel's Fund; Aase and Ejnar Danielsen's Fund; Augustinus Fund; Manufacturer Mads Clausen's Fund; Family Hede Nielsen's Fund; Else and Mogens Wedell-Wedellsborg's Fund; Carl and Ellen Hertz's Grant for Danish Medical and Natural Sciences Research; and Merchant Sven Hansen and Mrs Ina Hansen's Fund; no financial relationships with any organisations that might have an interest in the submitted work in the previous three years; JB, MR, and EL are currently undertaking a comparative study of new generation human papillomavirus tests, involving collaboration with Roche Diagnostics, Genomica, Qiagen Gaithersburg, and GenProbe.

Ethical approval: Not required.

Data sharing: No additional data available.

1 International Agency for Research on Cancer. IARC handbooks of cancer prevention. Vol 10: cenvix cancer screening. IARC Press, 2005.

2 Kinney W, Stoler MH, Castle PE. Special commentary: patient safety and the next generation of HPV DNA tests. Am J Clin Pathol 2010;134:193-9.

3 Rebolj M, Pribac I, Lynge E. False-positive human papillomavirus DNA tests in cervical screening: it is all in a definition. Eur J Cancer 2011;47:255-61.

4 Cuzick J, Arbyn M, Sankaranarayanan R, Tsu V, Ronco G, Mayrand MH, et al. Overview of human papillomavirus-based and other novel options for cervical cancer screening in developed and developing countries. Vaccine 2008;26:K29-41.

5 Bouvard V, Baan R, Straif K, Grosse Y, Secretan B, El Ghissassi F, et al. A review of human carcinogens-part B: biological agents. Lancet Oncol 2009;10:321-2.

6 Meijer CJ, Berkhof J, Castle PE, Hesselink AT, Franco EL, Ronco G, et al. Guidelines for human papillomavirus DNA test requirements for 
primary cervical cancer screening in women 30 years and older. Int Cancer 2009;124:516-20.

7 Ronco G, Giorgi-Rossi P, Carozzi F, Confortini M, Dalla Palma P, Del Mistro A, et al. Results at recruitment from a randomized controlled trial comparing human papillomavirus testing alone with conventional cytology as the primary cervical cancer screening test. JNCl 2008;100:492-501.

8 Mayrand MH, Duarte-Franco E, Rodrigues I, Walter SD, Hanley J, Ferenczy A, et al. Human papillomavirus DNA versus Papanicolaou screening tests for cervical cancer. N Engl/ Med 2007;357:1579-88.

9 Sargent A, Bailey A, Turner A, Almonte M, Gilham C, Baysson H, et al. Optimal threshold for a positive hybrid capture 2 test for detection of human papillomavirus: data from the ARTISTIC Trial. / Clin Microbiol 2010;48:554-8.

10 Kotaniemi-Talonen L, Malila N, Nieminen P, Anttila A, Tarkkanen J, Laurila $\mathrm{P}$, et al. Test positivity cutoff level of a high risk human papillomavirus test could be increased in routine cervical cancer screening. Int J Cancer 2008;123:2902-6.

11 Current Controlled Trials. Current Controlled Trials. 2011. www. controlled-trials.com.

12 US National Institutes of Health. ClinicalTrials.gov. 2011. www. clinicaltrials.gov/ct2/home.

13 Davies P, Arbyn M, Dillner J, Kitchener HC, Meijer CJ, Ronco G, et al. A report on the current status of European research on the use of human papillomavirus testing for primary cervical cancer screening. Int J Cancer 2006;118:791-6.

14 Kitchener HC, Almonte M, Gilham C, Dowie R, Stoykova B, Sargent A, et al. ARTISTIC: a randomised trial of human papillomavirus (HPV) testing in primary cervical screening. Health Technol Assess 2009;13:1-iv.

15 International Agency for Research on Cancer. Biennial report 08/09. 2009. www.iarc.fr/en/publications/pdfs-online/breport/ breport0809/breport0809.pdf.

16 BC Cancer Agency. HPV FOCAL study: investigative team. 2011. www. bccancer.bc.ca/PPI/Screening/Cervical/hpvfocal/ investigativeTeam/default.htm.

17 CCCaST-Canadian Cervical Cancer Screening Trial. Investigators. 2011. www.mcgill.ca/cccast/investigators.

18 Lynge E, Rebolj M. Primary HPV screening for cervical cancer prevention: results from European trials. Nat Rev Clin Oncol 2009;6:699-706.

19 Bulkmans NW, Rozendaal L, Snijders PJ, Voorhorst FJ, Boeke A), Zandwijken GR, et al. POBASCAM, a population-based randomized controlled trial for implementation of high-risk HPV testing in cervical screening: design, methods and baseline data of 44,102 women. Int J Cancer 2004;110:94-101.

20 Naucler P, Ryd W, Tornberg S, Strand A, Wadell G, Elfgren K, et al. Human papillomavirus and Papanicolaou tests to screen for cervical cancer. N Engl J Med 2007;357:1589-97.

21 Bais AG, van Kemenade FJ, Berkhof J, Verheijen RH, Snijders PJ, Voorhorst F, et al. Human papillomavirus testing on self-sampled cervicovaginal brushes: an effective alternative to protect nonresponders in cervical screening programs. Int / Cancer 2007;120:1505-10.

22 Ogilvie GS, van Niekerk DJ, Krajden M, Martin RE, Ehlen TG, Ceballos $\mathrm{K}$, et al. A randomized controlled trial of human papillomavirus (HPV) testing for cervical cancer screening: trial design and preliminary results (HPV FOCAL Trial). BMC Cancer 2010;10:111

23 Mayrand MH, Duarte-Franco E, Coutlee F, Rodrigues I, Walter SD, Ratnam S, et al. Randomized controlled trial of human papillomavirus testing versus Pap cytology in the primary screening for cervical cancer precursors: design, methods and preliminary accrual results of the Canadian cervical cancer screening trial (CCCaST). Int J Cancer 2006;119:615-23.

24 Sankaranarayanan R, Nene BM, Dinshaw KA, Mahe C, Jayant K, Shastri SS, et al. A cluster randomized controlled trial of visual, cytology and human papillomavirus screening for cancer of the cervix in rural India. Int J Cancer 2005;116:617-23.

25 Sankaranarayanan R, Nene BM, Shastri SS, Jayant K, Muwonge R, Budukh AM, et al. HPV screening for cervical cancer in rural India. $N$ Engl I Med 2009;360:1385-94.

26 Denny L, Kuhn L, De Souza M, Pollack AE, Dupree W, Wright TC Jr. Screen-and-treat approaches for cervical cancer prevention in lowresource settings: a randomized controlled trial. JAMA 2005;294:2173-81.

27 Ronco G, Giorgi-Rossi P, Carozzi F, Dalla Palma P, Del Mistro A, De Marco L, et al. Human papillomavirus testing and liquid-based cytology in primary screening of women younger than 35 years: results at recruitment for a randomised controlled trial. Lancet Oncol 2006;7:547-55.

28 Ronco G, Segnan N, Giorgi-Rossi P, Zappa M, Casadei GP, Carozzi F, et al. Human papillomavirus testing and liquid-based cytology: results at recruitment from the new technologies for cervical cancer randomized controlled trial. JNCI 2006;98:765-74.
29 Ronco G, Giorgi-Rossi P, Carozzi F, Confortini M, Dalla Palma P, Del Mistro A, et al. Efficacy of human papillomavirus testing for the detection of invasive cervical cancers and cervical intraepithelial neoplasia: a randomised controlled trial. Lancet Oncol 2010;11:249-57.

30 Anttila A, Kotaniemi-Talonen L, Leinonen M, Hakama M, Laurila P, Tarkkanen J, et al. Rate of cervical cancer, severe intraepithelia neoplasia, and adenocarcinoma in situ in primary HPV DNA screening with cytology triage: randomised study within organised screening programme. BMJ 2010;340:c1804

31 Dillner J, Rebolj M, Birembaut P, Petry KU, Szarewski A, Munk C, et al. Long term predictive values of cytology and human papillomavirus testing in cervical cancer screening: joint European cohort study. BMJ 2008;337:a1754.

32 Berkhof J, Coupe VM, Bogaards JA, van Kemenade FJ, Helmerhorst TJ, Snijders PJ, et al. The health and economic effects of HPV DNA screening in The Netherlands. Int J Cancer 2010;127:2147-58.

33 Bos AB, van Ballegooijen M, van Oortmarssen GJ, van Marle ME, Habbema JD, Lynge E. Non-progression of cervical intraepithelial neoplasia estimated from population-screening data. Br J Cancer 1997;75:124-30.

34 McCredie MR, Sharples KJ, Paul C, Baranyai J, Medley G, Jones RW, et al. Natural history of cervical neoplasia and risk of invasive cancer in women with cervical intraepithelial neoplasia 3: a retrospective cohort study. Lancet Oncol 2008;9:425-34.

35 Van Oortmarssen GJ, Habbema JD. Epidemiological evidence for agedependent regression of pre-invasive cervical cancer. Br / Cancer 1991;64:559-65.

36 Cuzick J, Szarewski A, Cubie H, Hulman G, Kitchener H, Luesley D, et al. Management of women who test positive for high-risk types of human papillomavirus: the HART study. Lancet 2003;362:1871-6.

37 Clavel C, Masure M, Bory JP, Putaud I, Mangeonjean C, Lorenzato M, et al. Human papillomavirus testing in primary screening for the detection of high-grade cervical lesions: a study of 7932 women. $\mathrm{Br}$ J Cancer 2001;84:1616-23.

38 Nieminen P, Vuorma S, Viikki M, Hakama M, Anttila A. Comparison of HPV test versus conventional and automation-assisted Pap screening as potential screening tools for preventing cervical cancer. Br/Obstet Gynaecol 2004;111:842-8.

39 Moy LM, Zhao FH, Li LY, Ma JF, Zhang QM, Chen F, et al. Human papillomavirus testing and cervical cytology in primary screening for cenvical cancer among women in rural China: comparison of sensitivity, specificity, and frequency of referral. Int J Cancer 2010;127:646-56

40 Rijkaart DC, Coupe VM, van Kemenade FJ, Heideman DA Hesselink AT, Verweij W, et al. Comparison of hybrid capture 2 testing at different thresholds with cytology as primary cervical screening test. Br/Cancer 2010;103:939-46.

41 Ratnam S, Coutlee F, Fontaine D, Bentley J, Escott N, Ghatage P, et al. Aptima HPV E6/E7 mRNA test is as sensitive as hybrid capture 2 assay but more specific at detecting cervical precancer and cancer. I Clin Microbiol 2011;49:557-64

42 Naucler P, Ryd W, Tornberg S, Strand A, Wadell G, Elfgren K, et al. Efficacy of HPV DNA testing with cytology triage and/or repeat HPV DNA testing in primary cervical cancer screening. JNCI 2009;101:88-99.

43 Hellsten C, Sjostrom K, Lindqvist PG. A 2-year follow-up study of anxiety and depression in women referred for colposcopy after an abnormal cenvical smear. BrJ Obstet Gynaecol 2008;115:212-8.

44 Castle PE, Schiffman M, Wheeler CM, Solomon D. Evidence for frequent regression of cervical intraepithelial neoplasia-grade 2. Obstet Gynecol 2009;113:18-25.

45 Ostor AG. Natural history of cervical intraepithelial neoplasia: critical review. Int J Gynecol Pathol 1993;12:186-92.

46 Arbyn M, Kyrgiou M, Simoens C, Raifu AO, Koliopoulos G, Martin-Hirsch $\mathrm{P}$, et al. Perinatal mortality and other severe adverse pregnancy outcomes associated with treatment of cervical intraepithelial neoplasia: meta-analysis. BMJ 2008;337:a1284.

47 Wardle J, Pope R. The psychological costs of screening for cancer. J Psychosom Res 1992;36:609-24.

48 Insinga RP, Glass AG, Myers ER, Rush BB. Abnormal outcomes following cervical cancer screening: event duration and health utility loss. Med Decis Making 2007;27:414-22.

49 Tombola Group. Cytological surveillance compared with immediate referral for colposcopy in management of women with low grade cervical abnormalities: multicentre randomised controlled trial. $B M$ 2009;339:b2546.

50 Office for Official Publications of the European Communities. European guidelines for quality assurance in cervical cancer screening. 2nd ed. Office for Official Publications of the European Communities, 2008.

Accepted: 28 March 201 